\title{
MATERNAL AND PERINATAL FACTORS AFFECTING CORD BLOOD THYROID STIMULATING HORMONE LEVEL
}

\author{
Vinoth Kumar S. P1, Peter Pathrose Vazhayil2, Indhiradevi Balusamy ${ }^{3}$
}

1Junior Resident, Department of Paediatrics, Government Medical College, Ernakulam, Kerala.

${ }^{2}$ Associate Professor, Department of Paediatrics, Government Medical College, Ernakulam, Kerala. 3Junior Resident, Department of Paediatrics, Government Medical College, Ernakulam, Kerala.

\section{ABSTRACT}

\section{BACKGROUND}

Incidence of Congenital Hypothyroidism in India is relatively high when compared to that of other parts of the world. The fact that only $5-10 \%$ can be diagnosed clinically signifies the role of screening program for early diagnosis and early initiation of therapy to treat this preventable cause of intellectual disability. Cord blood TSH (CB TSH) estimation has high sensitivity, but various maternal and perinatal factors affect the CB TSH levels, which may interfere with the interpretation.

This study was done to find out the various maternal and perinatal factors affecting CB TSH level.

\section{MATERIALS AND METHODS}

A hospital-based cross-sectional study was conducted in the Department of Neonatology, Govt. Medical College, Ernakulam over a period of one year from February 2016 to January 2017. We enrolled 127 live neonates selected by systematic random sampling method. Cord blood TSH level was estimated and the results were statistically analysed with respect to various maternal and perinatal factors.

\section{RESULTS}

Mean CB TSH in the study population was $9.713 \pm 7.286$. The risk factors for a significantly high CB TSH level were low Apgar at 1 minute, Preterm babies and Primigravida mothers $(\mathrm{p}<0.05)$. A significantly low CB TSH was noted in preterm neonates who received antenatal steroids $(\mathrm{p}<0.05)$. The other factors like gestational diabetes, gestational hypertension, gender of the baby, birth weight and meconium stained liquor were found to have no significant relationship with the CB TSH level.

\section{CONCLUSION}

Mainly low Apgar at 1 min which is an indicator of foetal distress/ perinatal asphyxia, prematurity and parity contributed to the significant elevation of CB TSH level. Antenatal steroids can significantly blunt the TSH surge. Due consideration should be given to these factors while interpreting CB TSH levels.

\section{KEY WORDS}

Congenital Hypothyroidism; Cord Blood Thyroid Stimulating Hormone; Newborn Screening; Maternal and Perinatal Factors.

HOW TO CITE THIS ARTICLE: Kumar VSP, Vazhayil PP, Balusamy I. Maternal and perinatal factors affecting cord blood thyroid stimulating hormone level. J. Evolution Med. Dent. Sci. 2018;7(19):2415-2419, DOI: 10.14260/jemds/2018/543

\section{BACKGROUND}

Congenital Hypothyroidism is the most common preventable cause of Intellectual Disability. The incidence of Congenital Hypothyroidism in India is $1: 2500$ to $1: 2800$ live births, which is higher when compared to the worldwide incidence of 1:3000 - 4000.(1),(2) Most infants with congenital hypothyroidism seem to be unaffected at birth, because of placental transfer of thyroid hormones. Only 5-10\% of children can be diagnosed clinically, which signifies the role of screening program for early diagnosis and treatment to prevent the adverse outcome.(3)

Newborn screening program for congenital hypothyroidism was introduced by ICMR at various centres since 2007. It measures Thyroid stimulating hormone (TSH) level in either cord blood sample or that obtained from

'Financial or Other Competing Interest': None.

Submission 27-03-2018, Peer Review 24-04-2018,

Acceptance 30-04-2018, Published 07-05-2018.

Corresponding Author:

Dr. Peter Pathrose Vazhayil,

Associate Professor,

Department of Paediatrics, Government Medical College,

Kalamassery, Ernakulam-683503, Kerala.

E-mail: drpeter123@yahoo.com

DOI: $10.14260 /$ jemds/2018/543

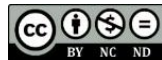

blood sample at 3 to 4 days of life. As a screening tool, Cord Blood Thyroid Stimulating Hormone (CB TSH) has a high sensitivity, but with a high false positive rate. Various maternal and perinatal factors are known to affect CB TSH levels.(4) Armanian AM et al and Durga et al reported that perinatal stress factors and mode of delivery can affect the level of cord blood TSH.(5),(6) However, Yozenfuse et al and Tabassum $\mathrm{Y}$ et al have shown that mode of delivery, gestational diabetes, birth weight and Apgar score have no significant relationship with cord blood TSH level.(7),(8) Thus, studies reported by different authors about the relationship between perinatal factors and cord blood TSH levels have not been consistent and only few studies were done in India on the same. So this study attempts to find out various maternal and perinatal factors affecting CB TSH levels, which may add further evidence to the existing knowledge.

\section{MATERIALS AND METHODS}

This is a hospital-based cross-sectional study done in the Department of Neonatology, Government Medical College, Ernakulam over a period of 1 year from February 2016 to January 2017. The study included all the live newborn babies delivered at our hospital during the study period. Neonates with major life-threatening malformations, antenatally detected central nervous system malformations, mothers 
who were on treatment with anti-thyroid drugs and babies whose blood samples could not be studied due to technical reasons (Inadequate sample or haemolysed sample) were excluded from the study. The samples were chosen by systematic random sampling method on alternate day to a minimum of 10 samples per month until the sample size was met. Informed written parental consent was obtained from all cases at birth and babies were enrolled in the study. Information was collected from the maternal case records and neonatal database recorded in Neonatal ICU. Data entered into a pretested semi-structured questionnaire, which included socio-demographic details of the mothers, details of antenatal period and delivery including date and time of birth, order of birth, gestational age, birth weight, sex of the baby and type of delivery. Maternal and perinatal details like maternal medical illness (Gestational diabetes and gestational hypertension), antenatal steroid history, colour of liquor were collected from mother's records. Baby's weight was measured by digital weighing machine within 1 hour of birth. Apgar score was assessed by skilled residents at 1 and 5 minutes. Apart from the cord blood which was routinely collected for blood grouping, an extra $2 \mathrm{~mL}$ of blood was obtained for TSH assay from the maternal end of umbilical cord immediately after clamping. The sample was preserved at room temperature and transported to the laboratory within 1 hour. The samples were analysed within 3 hours using the ultrasensitive sandwich chemiluminescent immunoassay. All neonates who had CB TSH levels more than $20 \mu \mathrm{IU} / \mathrm{mL}$, repeat TSH and TT4 levels were done within 14 days of life, preferably after 72 hours. While some variables in the proforma are self-explanatory, definitions for other relevant major variables are as follows: Parity- According to the order of birth first gravida was categorised as primipara and $\geq 2^{\text {nd }}$ gravida as multipara. Gestational age: Gestational age was calculated from LMP obtained from maternal records using Naegele's rule and confirmed with gestational age assessment by Ballard's scoring. Then classified into Term$37^{+0}$ to 42 weeks, Post Term- 42 weeks and beyond, Late Preterm- $34^{+0}$ to $36^{+6}$ weeks, Moderate Preterm- $32^{+0}$ to $33^{+6}$ weeks, Very Preterm- $28^{+0}$ to $31^{+6}$ weeks, Extreme Preterm$<28$ weeks. Birth Weight: Weight was measured within 1 hour of birth using a digital scale in grams and categorised as < 1000 gm; 1000 - 1499 gm; 1500 - 2499 gm; 2500 - 3999 gm; > 4000 gm. Type of Delivery: Classified as vaginal/caesarean section. Gestational hypertension- It includes those mother who were diagnosed to have hypertension (BP > 140/90 mmHg) first time after 20 weeks of gestation.(9) Gestational Diabetes (GDM: Any degree of glucose intolerance with onset or first recognition during pregnancy.(10) Meconium stained amniotic fluid- According to the colour of liquor, it was classified as Meconium stained/clear. Apgar at 1 and 5 mins- Apgar score was calculated by evaluating the newborn's appearance, pulse, grimace, activity and respiration at 1 and $5 \mathrm{mins}$ and classified as Apgar $<7$ and $>7$.

Data was entered after giving code for each variable into a master chart in Microsoft Excel 2010 and analysed using appropriate statistical software (SPSS version 20). Independent sample ' $t$ ' test and ANOVA test were used to find the relationship between the factors and cord blood TSH.

\section{RESULTS}

Out of 127 babies included in the study, $52.8 \%$ were male and $47.2 \%$ were female and the male-to-female ratio was 1.1: 1 . $25.2 \%$ were born to primigravida and $74.8 \%$ were born to multigravida mother. Majority (74.8\%) of the babies had CB TSH $<10.18 .9 \%$ of the babies had values between 10 and 20 and $6.3 \%$ belonged to the group $>20$ (Figure 1). The average CB TSH of the study population was 9.713 with standard deviation 7.286 and median 8.130. The minimum and maximum CB TSH was 3.1 and 60.1 respectively. $81.1 \%$ of the cases were term and $18.9 \%$ were preterm. Gestational age and Birth weight distribution is shown in Table 1.

In the study population $81.1 \%$ did not warrant steroids, as they were term deliveries. In preterm babies, 14 (11.0\%) had received antenatal steroids and 10 (7.9\%) did not receive antenatal steroids. 12 (9.4\%) pregnancies were complicated by gestational hypertension, 11 (8.6\%) by GDM and $9(7.1 \%)$ by meconium stained liquor. The proportion of vaginal deliveries in the study group was $41.7 \%$, which included spontaneous vaginal (36.2\%), induced (4.7\%) and instrumental $(0.8 \%)$. Among the remaining $58.3 \%$ of the cases of LSCS elective, LSCS was done in $(22.8 \%)$ and emergency LSCS in (35.4\%). 5 (3.9\%) had Apgar at 1 minute below 7. The minimum and maximum Apgar was 3 and 9 respectively. Out of 127 babies, only $1(0.8 \%)$ had Apgar at 5 minutes below 7 and $99.2 \%$ have Apgar at 1 minute above 7 .

The relationships of CB TSH to various maternal factors are shown in Table 2 and 3 . We found that there is significant relationship between $\mathrm{CB}$ TSH and parity, $\mathrm{CB}$ TSH and gestational age (weeks), CB TSH and antenatal steroids, CB TSH and Apgar at 1 minute $(\mathrm{p}<0.05)$. The table reveals that CB TSH is significantly higher in primigravida compared to multigravida, CB TSH was significantly higher in $28-31$ weeks ( $42.6 \pm 0.00$ ) compared to 32 - 33 weeks $(13.1 \pm 10.8)$, $34-36$ weeks ( $9.45 \pm 5.97)$ and $37-42$ weeks $(9.31 \pm 6.68)$. CB TSH was significantly higher in preterms who had not received antenatal steroids (17.1 \pm 12.6$)$ compared to preterms who had received antenatal steroids $(7.43 \pm 2.62)$. There was no significant relation between $\mathrm{CB}$ TSH and gestational hypertension, CB TSH and gestational diabetes, CB TSH and type of delivery, CB TSH and meconium stained liquor, CB TSH and gender, CB TSH and birth weight ( $\mathrm{p}>$ $0.05)$. The table reveals that CB TSH is higher in 1500-2499 (10.8 \pm 8.13) and 2500-3999 (9.38 \pm 6.99) compared to $>4000(5.27 \pm 1.25)$, but $p$-value (0.421) suggests that it is not significant.

\begin{tabular}{|c|c|c|}
\hline Gestational Age (Weeks) & Frequency & Percent \\
\hline$<28$ & 0 & $0.0 \%$ \\
\hline $28-31$ & 1 & $0.8 \%$ \\
\hline $32-33$ & 4 & $3.1 \%$ \\
\hline $34-36$ & 19 & $15.0 \%$ \\
\hline $37-42$ & 103 & $81.1 \%$ \\
\hline Birth Weight (Grams) & & \\
\hline$<1000$ & 0 & $0.0 \%$ \\
\hline $1000-1499$ & 0 & $0.0 \%$ \\
\hline $1500-2499$ & 35 & $27.6 \%$ \\
\hline $2500-3999$ & 90 & $70.9 \%$ \\
\hline$>4000$ & 2 & $1.6 \%$ \\
\hline Table 1. Gestational Age and Birth Weight Distribution
\end{tabular}

Table 1. Gestational Age and Birth Weight Distribution 


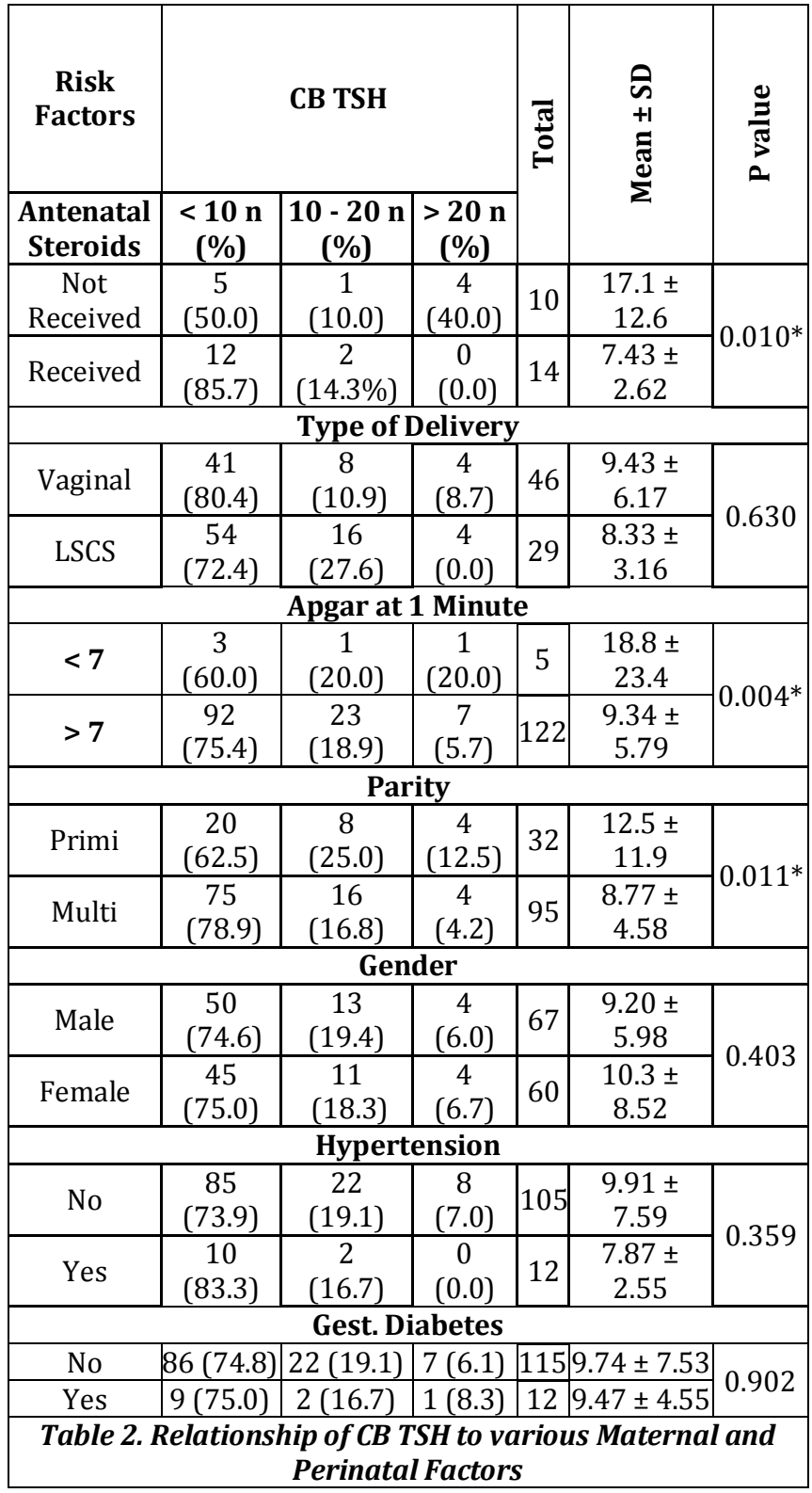

\begin{tabular}{|c|c|c|c|c|c|c|}
\hline \multirow{2}{*}{$\begin{array}{c}\text { Gestation } \\
\text { al Age } \\
\text { (Weeks) }\end{array}$} & \multicolumn{3}{|c|}{ CB TSH } & \multirow{2}{*}{ 퓸 } & \multirow{2}{*}{$\begin{array}{c}\text { Mean } \pm \\
\text { SD }\end{array}$} & \multirow{2}{*}{$\begin{array}{c}\text { P- } \\
\text { value }\end{array}$} \\
\hline & $<10$ & $10-20$ & $>20$ & & & \\
\hline $28-31$ & $\begin{array}{c}0 \\
(0.0 \%)\end{array}$ & $\begin{array}{c}0 \\
(0.0 \%)\end{array}$ & $\begin{array}{c}1 \\
(100.0 \%)\end{array}$ & 1 & $\begin{array}{c}42.6 \pm \\
0.00\end{array}$ & \multirow{4}{*}{$\begin{array}{c}0.001 \\
*\end{array}$} \\
\hline $32-33$ & $\begin{array}{c}3 \\
(75.0 \%)\end{array}$ & $\begin{array}{c}0 \\
(0.0 \%)\end{array}$ & $\begin{array}{c}1 \\
(25.0 \%)\end{array}$ & 4 & $\begin{array}{c}13.1 \pm \\
10.8\end{array}$ & \\
\hline $34-36$ & $\begin{array}{c}14 \\
(73.7 \%)\end{array}$ & $\begin{array}{c}3 \\
(15.8 \%)\end{array}$ & $\begin{array}{c}2 \\
(10.5 \%)\end{array}$ & 19 & $\begin{array}{c}9.45 \pm \\
5.97\end{array}$ & \\
\hline $37-42$ & $\begin{array}{c}78 \\
(75.7 \%)\end{array}$ & $\begin{array}{c}21 \\
(20.4 \%)\end{array}$ & $\begin{array}{c}4 \\
(3.9 \%)\end{array}$ & 103 & $\begin{array}{c}9.31 \pm \\
6.68\end{array}$ & \\
\hline \multicolumn{7}{|c|}{ Birth Weight (Grams) } \\
\hline $\begin{array}{c}1500- \\
2499\end{array}$ & $\begin{array}{c}24 \\
(68.6 \%)\end{array}$ & $\begin{array}{c}7 \\
(20.0 \%)\end{array}$ & $\begin{array}{c}4 \\
(11.4 \%)\end{array}$ & 35 & $\begin{array}{c}10.8 \pm \\
8.13\end{array}$ & \multirow{3}{*}{0.421} \\
\hline $\begin{array}{c}2500- \\
3999\end{array}$ & $\begin{array}{c}69 \\
(76.7 \%)\end{array}$ & $\begin{array}{c}17 \\
(18.9 \%)\end{array}$ & $\begin{array}{c}4 \\
(4.4 \%)\end{array}$ & 90 & $\begin{array}{c}9.38 \pm \\
6.99\end{array}$ & \\
\hline$>4000$ & $\begin{array}{c}2 \\
(100.0 \%)\end{array}$ & $\begin{array}{c}0 \\
(0.0 \%)\end{array}$ & $\begin{array}{c}0 \\
(0.0 \%)\end{array}$ & 2 & $\begin{array}{c}5.27 \pm \\
1.25\end{array}$ & \\
\hline & & hip of & SH to & & & \\
\hline
\end{tabular}

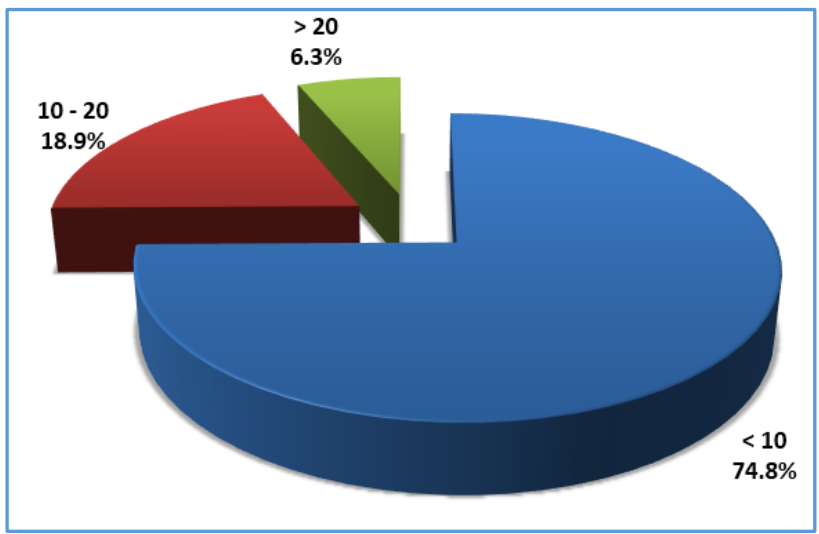

Figure 1. CB TSH Level in the Study Group

\section{DISCUSSION}

This study attempted to find out the various maternal and perinatal factors that influence the CB TSH level, thereby adding further evidence to the existing knowledge. The average CB TSH value among the study group was 9.713 with standard deviation of 7.286 and median value of 8.130 . The minimum and maximum CB TSH was $3.1 \mu \mathrm{IU} / \mathrm{mL}$ and 60.1 $\mu \mathrm{IU} / \mathrm{mL}$ respectively. Our result is consistent with the mean TSH value of the previous studies conducted by Singh et al $8.833 \pm 7.059 \mu \mathrm{IU} / \mathrm{mL}^{(11)}$ and Mekonen $\mathrm{Y}$ et al $9.6 \pm 5.27$ $\mu \mathrm{IU} / \mathrm{mL} .{ }^{(12)}$

In our study, we observed a decreasing trend of mean TSH when the gestational age increases. The mean value of CB TSH was significantly higher in 28 - 31 weeks compared to 32 - 33 weeks, 34 - 36 weeks and $37-42$ weeks $(p=0.001)$ This correlates with the study by Tabassum et al,(8) wherein a similar trend was observed, but studies conducted by Kim et al and Raj $S$ et al(13),(14) showed a reverse trend, in which term babies had higher mean CB TSH.

In our study, we divided preterm babies further into those who received and did not receive antenatal steroids to study the effect of administration of antenatal steroid. The existing evidence of animal studies by Fletcher et al and Jellyman et al(15),(16) suggests that steroids can suppress the HPT stimulatory action of endogenous catecholamines, which ultimately blunt the rise and lowers the TSH level. Not many studies were done previously to assess the relationship between antenatal steroids and CB TSH in humans. The mean CB TSH was low in those who received antenatal steroids $7.43 \pm 2.62$ than those who did not receive $17.1 \pm 12.6$ with a statistically significant $p$-value of 0.010 . Though, we could not measure the catecholamine levels, this study can support the inference of the existing studies indirectly by the observation of low level of TSH in those who received antenatal steroids.

According to our study, there was no significant relationship between sex of the baby and CB TSH. This results correlates with the studies by Armanian et al, Kim et al(13) and Lee et $\mathrm{al}^{(17)}$ and contradicts the study by Chan et al,(18) wherein the male babies had higher mean CB TSH value.

We found a statistically significant relationship between CB TSH and birth order. The CB TSH was high in primigravida mothers compared with multigravida. This result coincides with the studies of Durga et al and Gupta et al.(6,19) Though, the exact reason behind this is unknown, it may be attributed to the stress encountered by primigravida mothers compared to multigravida. 
We did not observe a significant relationship between CB TSH and Birth weight which supports the previous studies done by Gupta $\mathrm{M}$ et al,(19) RC Franklin et al,(4) Fuse $\mathrm{Y}$ et al and Joshi G et al.(20) Similar results were also observed with $\mathrm{CB}$ TSH and gestational diabetes and CB TSH and gestational hypertension as observed in studies by RC Franklin et al(4) and Gupta M et al.(19) Deliveries complicated by meconium stained liquor also did not show a significant relationship to CB TSH similar to the study by Raj et al.(14)

Mode of delivery is one of the common variables analysed in relation to $\mathrm{CB}$ TSH by various authors, but with the conflicting results. Being a tertiary care centre large number of high risk and emergency cases are handled here which may be attributable to the high number of LSCS (58.3\%). Similar to studies by Herbstman et al,(21) we did not find any significant relationship between $\mathrm{CB}$ TSH and mode of delivery.

Being an indicator of Birth asphyxia/ Perinatal depression, Apgar score was studied to know the relationship with CB TSH. In our study 5 out of 127 babies had $1^{\text {st }}$ minute Apgar of $<7$ with the mean CB TSH of $18.8 \pm 23.4$, which is very high when compared to that of babies with normal Apgar $(9.34 \pm 5.79)$. The p-value of 0.004 suggests that low Apgar at $1 \mathrm{~min}$ has statistically significant relationship with CB TSH. Similar result was observed in studies by Kim EY et al,(13) Durga et al(6) and Gupta et al.(19)

Among the study population, 8 (6.30\%) were detected to have suspected congenital hypothyroidism (CB TSH > 20 $\mu \mathrm{IU} / \mathrm{mL}$ ) with a mean value of $32.99 \pm 12.68$. But their repeat value after the immediate neonatal stressful period was normal. Hence, there were no confirmed cases of congenital hypothyroidism in the study population.

\section{CONCLUSION}

Our study found that Apgar at 1 minute, gestational age, parity and antenatal steroid exposure had significant relationship with the $\mathrm{CB}$ TSH level. Hence, the above said factors should be considered when CB TSH level is used for congenital hypothyroidism screening.

\section{Limitations}

We screened only the CB TSH and not the CB T4 level. Though the occurrence is rare, it may not detect central hypothyroidism, thyroid binding globulin (TBG) deficiency and hypothyroxinaemia with delayed elevation of TSH. Our study was a single centre based. Study needs to be conducted as a multicentric one with more number of cases to get more data.

\section{REFERENCES}

[1] Desai MP, Colaco MP, Ajgaonkar AR, et al. Neonatal screening for congenital hypothyroidism in a developing country: problems and strategies. Indian J Pediatr 1987;54(4):571-81.

[2] Manglik AK, Chatterjee N, Ghosh G. Umbilical cord blood TSH levels in term neonates: a screening tool for congenital hypothyroidism. Indian Pediatr 2005;42(10):1029-32.

[3] Devi RAR, Naushad SM. Newborn screening in India. Indian J Pediatr 2004;71(2):157-60.

[4] Franklin RC, Carpenter LM, O'Grady CM. Neonatal thyroid function: influence of perinatal factors. Arch Dis Child 1985;60(2):141-4.
[5] Armanian AM, Hashemipour M, Esnaashari A, et al. Influence of perinatal factors on thyroid stimulating hormone level in cord blood. Adv Biomed Res 2013;2:48.

[6] Durga D, Rudrappa S, Kumar R, et al. Prenatal factors influencing the interpretation of cord blood thyroid stimulating hormone levels. International Journal of Scientific Study 2015;2(12):104-9.

[7] Fuse Y, Wakae E, Nemoto Y, et al. Influence of perinatal factors and sampling methods on TSH and thyroid hormone levels in cord blood. Endocrinology Japan 1991;38(3):297-302.

[8] Tabassum Y, Shafat IS, Prasad KR, et al. Effect of neonatal thyroid stimulating hormone and free $\mathrm{T} 4$ levels on Apgar score, maturity and modes of delivery. Intern J Med Science and Clinical Research 2014;2(5):890-5.

[9] Visintin C, Mugglestone MA, Almerie MQ, et al. Management of hypertensive disorders during pregnancy: summary of NICE guidance. BMJ 2010;341:c2207.

[10] Metzger BE, Coustan DR. Proceedings of the Fourth International Work-shop-Conference on Gestational Diabetes Mellitus. Diabetes Care 1998;21(Suppl 2):B1B167.

[11] Singh PK, Parvin CA, Gronowski AM. Comment: establishment of reference intervals for markers of fetal thyroid status in amniotic fluid. The Journal of Clinical Endocrinology \& Metabolism 2003;88(9):4175-9.

[12] Mekonnen Y, Gizachew WH, Chamiso B, et al. Thyroid stimulating hormone values in cord blood in neonates. Ethiop J Health Dev 2003;17(2):125-30.

[13] Kim EY, Park SK, Song $\mathrm{CH}$, et al. Perinatal factors affecting thyroid stimulating hormone TSH and thyroid hormone levels in cord blood. Korean J Pediatri 2005;48(2):143-7.

[14] Raj S, Baburaj S, George J, et al. Cord blood TSH level variations in newborn - experience from a rural centre in southern India. J Clin Diagn Res 2014;8(7):PC18-20.

[15] Fletcher AJ, Gardner DS, Edwards CM, et al. Cardiovascular and endocrine responses to acute hypoxaemia during and following dexamethasone infusion in the ovine fetus. J Physiol 2003;549(Pt 1):271-87.

[16] Jellyman JK, Gardner DS, Edwards CM, et al. Fetal cardiovascular, metabolic and endocrine responses to acute hypoxaemia during and following maternal treatment with dexamethasone in sheep. J Physiol 2005;567(Pt 2):673-88.

[17] Lee SY. Perinatal factors associated with neonatal thyroid-stimulating hormone in normal newborns. Ann Pediatr Endocrinol Metab 2016;21(4):206-11.

[18] Chan LY, Chiu PY, Lau TK. Cord blood thyroid stimulating hormone level in high-risk pregnancies. Eur J Obstet Gynecol Reprod Biol 2003;108(2):142-5.

[19] Gupta A, Srivastava S, Bhatnagar A. Cord blood thyroid stimulating hormone level - interpretation in light of perinatal factors. Indian Pediatr 2014;51(1):32-6. 
[20] Joshi G, Menon R. Profile of umbilical cord blood TSH $\mathrm{T}_{4}$ and influence of perinatal factors on thyroid functions in Newborns. J Clin Biomed Sci 2014;4(2):282-5.
[21] Herbstman J, Apelberg BJ, Witter FR, et al. Maternal, infant and delivery factors associated with neonatal thyroid hormone status. Thyroid 2008;18(1):67-76. 